\title{
Efficient Synthesis of Highly Enantioenriched $\Delta^{\mathbf{1}}$-Pyrrolines
}

\author{
Diana I. S. P. Resende ${ }^{a}$ \\ Samuel Guieu ${ }^{\mathrm{a}, \mathrm{b}}$ \\ Cristina G. Oliva*a,1 \\ Artur M. S. Silva*a \\ a Department of Chemistry, QOPNA, University of Aveiro, \\ 3810-193 Aveiro, Portugal \\ b Department of Chemistry, CICECO, University of Aveiro, \\ 3810-193 Aveiro, Portugal \\ artur.silva@ua.pt
}

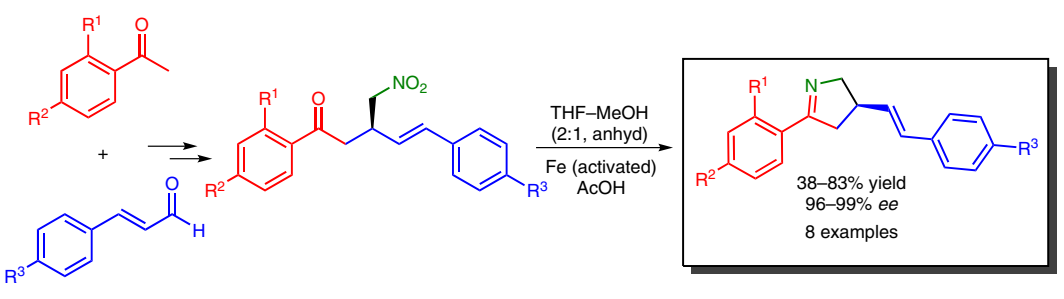

Received: 27.11.2014

Accepted after revision: 14.01.2015

Published online: 17.02 .2015

DOI: 10.1055/s-0034-1380144; Art ID: st-2014-d0977-I

Abstract A general and efficient asymmetric synthesis of $\Delta^{1}$-pyrrolines by a one-pot nitro-reduction, cyclization, and dehydration of $(R, E)-1,5$ diphenyl-3-(nitromethyl)-5-pent-4-en-1-ones with iron and aqueous hydrochloric acid has been developed. The $\Delta^{1}$-pyrrolines were obtained with excellent enantioselectivities (up to 99\%) and high yields (up to $83 \%)$.

Key words pyrrolines, reductive cyclization, Michael addition, stereoselectivity

Nitrogen-containing heterocycles are important core structures in natural and synthetic biologically active compounds. ${ }^{2,3}$ In particular, 3,4-dihydro-2H-pyrroles, ${ }^{4}$ also called $\Delta^{1}$-pyrrolines, can be found in a wide variety of bio- logically active compounds such as hemes, chlorophylls and alkaloids, and these rings have been used as building blocks for the development of new drugs. ${ }^{4}$ Recently, our group reported the synthesis of new boranil derivatives based on a $\Delta^{1}$-pyrroline core leading to new fluorophores. ${ }^{5}$ The synthesis of $\Delta^{1}$-pyrrolines is well documented ${ }^{2,4,6,7}$ and usually involves reductive cyclization of $\gamma$-nitro carbonyl compounds. ${ }^{8,9}$ However, asymmetric versions of these reactions are scarce. ${ }^{10,11}$ Shibata et al. ${ }^{10}$ have recently reported the enantioselective synthesis of $\beta$-trifluoromethylated pyrrolines through organocatalyzed-conjugate addition of nitromethane to $\beta$-trifluoromethylated enones, followed by a nitroreduction, cyclization and dehydration sequence in a onepot procedure. Despite the very straightforward methodology, the need for a trifluoromethyl group restricts its scope and limits its application to particular cases.<smiles>[R]c1ccc(C(=O)/C=C/C=C/c2ccc(PC)cc2)c([R])c1</smiles>

$\mathrm{R}^{1}=\mathrm{H}, \mathrm{OH}, \mathrm{NH}_{2}$ $\mathrm{R}^{2}=\mathrm{H}, \mathrm{Me}, \mathrm{OMe}, \mathrm{Cl}, \mathrm{Br}, \mathrm{F}, \mathrm{CN}$ $\mathrm{R}^{3}=\mathrm{H}, \mathrm{OMe}, \mathrm{NO}_{2}$<smiles>[R]c1ccc(/C=C/C(CC(=O)c2ccc([R7])cc2[R])C[N+](=O)[O-])cc1</smiles>

$(R)-3$

yield $19-97 \%$; ee $87-99 \%$ after recrystallization $e e>99 \%$

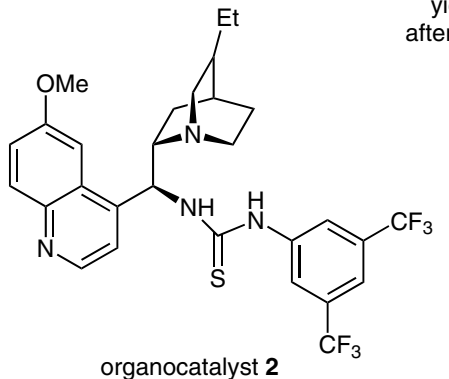

Scheme 1 Enantioselective addition of nitromethane to (E,E)-1,5-diarylpenta-2,4-dien-1-ones 1 organocatalyzed by 2 
Table 1 Screening of Reduction Methods on the One-Pot Nitro-Reduction, Cyclization and Dehydration of (R)-3a

\begin{tabular}{|c|c|c|c|c|c|}
\hline \multirow[t]{2}{*}{ Entry } & \multirow[t]{2}{*}{ Conditions } & \multirow[t]{2}{*}{ Temp. $\left({ }^{\circ} \mathrm{C}\right)$} & \multirow[t]{2}{*}{ Time (h) } & \multicolumn{2}{|c|}{ Yield (\%) } \\
\hline & & & & $(R)-4 a$ & $(R)-5 \mathbf{a}$ \\
\hline $1^{\mathrm{a}}$ & DMF- $\mathrm{H}_{2} \mathrm{O}(1: 1), \mathrm{Zn}$, conc. $\mathrm{HCl}$ & 80 & 30 & 5 & 15 \\
\hline $2^{b}$ & $\mathrm{CHCl}_{3}$, Sn, concd $\mathrm{HCl}$ & r.t. & 15 & 31 & 35 \\
\hline $3^{c}$ & THF-MeOH (2:1), Fe, AcOH & 65 & 15 & 58 & 10 \\
\hline $4^{c}$ & THF-MeOH (2:1), Fe (activated), AcOH & 65 & 15 & 63 & 17 \\
\hline $5^{c}$ & THF-MeOH (2:1, anhyd), Fe (activated), AcOH & 65 & 15 & 72 & 8 \\
\hline $6^{c}$ & THF-MeOH (2:1), Fe (activated), AcOH & 80 & 15 & 36 & 14 \\
\hline
\end{tabular}

a Reaction conditions: $3 \mathrm{a}(0.169 \mathrm{mmol})$, concd $\mathrm{HCl}(0.34 \mathrm{~mL})$, Zn powder $(0.846 \mathrm{mmol}), \mathrm{DMF}-\mathrm{H}_{2} \mathrm{O}(1: 1,0.34 \mathrm{~mL}), 80^{\circ} \mathrm{C}, 30 \mathrm{~h}$.

${ }^{b}$ Reaction conditions: $3 a(0.169 \mathrm{mmol})$, concd $\mathrm{HCl}(5.6 \mathrm{~mL})$, Sn powder $(14.0 \mathrm{mmol}), \mathrm{CHCl}_{3}(15 \mathrm{~mL})$, r.t., 15 h.

' Reaction conditions: $3 a(0.31 \mathrm{mmol}), \mathrm{AcOH}(4.98 \mathrm{mmol}), \mathrm{Fe}(14.0 \mathrm{mmol}), \mathrm{THF}-\mathrm{MeOH}(2: 1,6 \mathrm{~mL}), 65^{\circ} \mathrm{C}, 15 \mathrm{~h}$, nitrogen atmosphere.

Recent studies in our laboratory have led to the development of a new methodology for the asymmetric 1,4-Michael addition of nitromethane to 1,5-diarylpenta-2,4dien-1-ones 1 (Scheme 1). ${ }^{12,13}$ In the presence of organocatalyst $\quad 2, \quad(R, E)$-1,5-diaryl-3-(nitromethyl)-5-pent-4-en-1ones $(R)-3$ have been obtained with excellent enantioselectivity (up to 99\%) and isolated yields (up to $97 \%$ ). We then wished to go one step further, and use these enantiomerically pure compounds for the synthesis of enantiopure $\Delta^{1}$ pyrroline derivatives. In this communication, we present a general methodology for the synthesis of several highly enantioenriched $\Delta^{1}$-pyrroline derivatives through a one-pot, nitro-reduction, cyclization, dehydration of the $(R, E)-1,5-$ diaryl-3-(nitromethyl)-5-pent-4-en-1-ones 3.

To investigate the reactivity of the $(R, E)$-1,5-diaryl-3(nitromethyl)-5-pent-4-en-1-ones 3 towards the reductive cyclization of the nitro group, our investigation began with a screening of metal-mediated reduction methods that have already been described (Scheme 2,Table 1)., ${ }^{9,10,14}$ The first two reductive systems examined involved $\mathrm{Zn} / \mathrm{HCl}$ (entry 1 ) and $\mathrm{Sn} / \mathrm{HCl}$ (entry 2) and the $\Delta^{1}$-pyrroline $4 a$ was obtained in low yields (5-31\%). Nevertheless, through HPLC analysis, it was possible to note the absence of racemization of the asymmetric carbon, which allowed us to obtain $\Delta^{1}$-pyrroline 4a in excellent enantiomeric excess (>99\%). However, formation of the corresponding $\Delta^{1}$-pyrroline- $N$-oxide $\mathbf{5 a}$ was also observed, in amounts higher than the desired product. Finally, reduction with $\mathrm{Fe} / \mathrm{AcOH}$ provided better results, and $\Delta^{1}$-pyrroline $4 a$ was obtained in good yield (entry 3). Further studies on the influence of the temperature, absence of water and oxygen, as well as the use of preactivated iron ${ }^{15}$ were performed (entries $4-6$ ). The best results were obtained by using a mixture of anhydrous tetrahydrofuran and methanol (2:1) under nitrogen, activated iron (14 $\mathrm{mmol})$ as reducing agent, and acetic acid $(4.98 \mathrm{mmol})$ as a proton source.

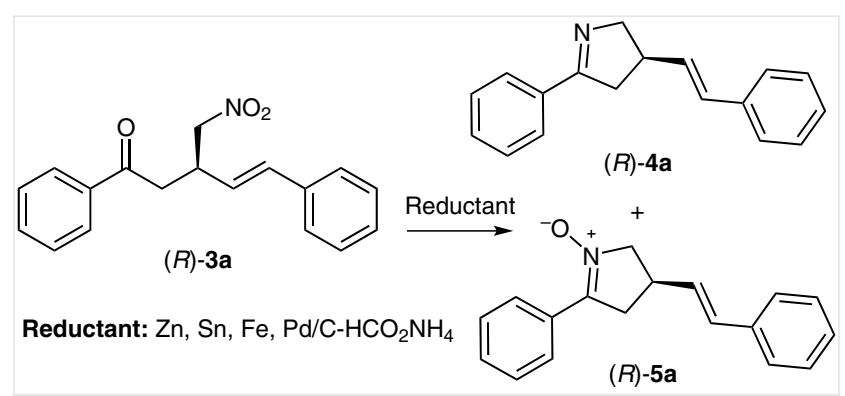

Scheme 2 Reduction methods tested on the one-pot nitro-reduction, cyclization, dehydration of (R,E)-1,5-diaryl-3-(nitromethyl)-5-pent-4en-1-ones 3

It is worth mentioning that, under these conditions, not only was the $\Delta^{1}$-pyrroline $\mathbf{4 a}$ obtained in a very good yield (72\%), but the formation of $\Delta^{1}$-pyrroline- $N$-oxide $\mathbf{5 a}$ was reduced to only $8 \%$ yield.

Table 2 Scope of the One-Pot Nitro-Reduction, Cyclization and Dehydration of $\mathbf{3}^{\mathrm{a}}$

\begin{tabular}{|c|c|c|c|c|c|c|}
\hline Entry & 3 & $\mathrm{R}^{1}$ & $\mathrm{R}^{2}$ & $\begin{array}{l}\text { Yield }(R)-4 \\
(\%)\end{array}$ & $\begin{array}{l}\text { ee }(R)-4 \\
(\%)\end{array}$ & $\begin{array}{l}\text { Yield }(R)-5 \\
(\%)\end{array}$ \\
\hline 1 & $3 b$ & $\mathrm{Me}$ & $\mathrm{H}$ & 83 & $>99$ & 6 \\
\hline 2 & $3 c$ & OMe & $\mathrm{H}$ & 73 & $>99$ & 11 \\
\hline 3 & $3 d$ & $\mathrm{Cl}$ & $\mathrm{H}$ & 49 & $>99$ & 5 \\
\hline 4 & $3 e$ & $\mathrm{~F}$ & $\mathrm{H}$ & 67 & $>99$ & 6 \\
\hline 5 & $3 f$ & $\mathrm{Br}$ & $\mathrm{H}$ & 44 & $>99$ & 9 \\
\hline 6 & $3 g$ & $\mathrm{NO}_{2}$ & $\mathrm{H}$ & $40^{\mathrm{b}}$ & $>99$ & $0^{c}$ \\
\hline 7 & $3 \mathrm{~h}$ & $\mathrm{H}$ & OMe & 38 & $>99$ & 4 \\
\hline
\end{tabular}

a Reaction conditions: $3 \mathbf{b}-\mathbf{h}$ (0.31 mmol), AcOH (4.98 mmol), Fe (14.0 $\mathrm{mmol})$, THF-MeOH $(2: 1,6 \mathrm{~mL}), 65^{\circ} \mathrm{C}, 15 \mathrm{~h}$, nitrogen atmosphere.

${ }^{\mathrm{b}}(R, E)$-2-(4-Aminophenyl)-4-styryl- $\Delta^{1}$-pyrroline $(\mathbf{4 g})$ was obtained.

c $(R, E)$-1-(4-Aminophenyl)-3-(nitromethyl)-5-phenyl-5-pent-4-en-1-one (3i) was obtained in $57 \%$ yield. 
848

Synlett

D. I. S. P. Resende et al.

Letter

After establishing these optimal reaction conditions, the scope of the reaction was investigated by using a range of derivatives 3b-h (Scheme 3, Table 2). The $\Delta^{1}$-pyrrolines $(R)$ $\mathbf{4 b}-\mathbf{h}^{16}$ were obtained in moderate to good yields (38-83\%) and excellent enantiomeric excesses (99\%) for all the synthesized derivatives (entries 1-7).

In the case of nitro derivative $\mathbf{3 g}$ (Table 2, entry 6), it was observed that reduction of the aromatic nitro group resalted in the formation of $(R, E)-2$-(4-aminophenyl)-4-stycyl- $\Delta^{1}$-pyrroline (Ag). Furthermore, for this derivative, the corresponding $N$-oxide $(R)-\mathbf{5}$ was not formed; instead, $(R, E)-1-(4-a m i n o p h e n y l)-3$-(nitromethyl)-5-phenyl-5-pent4-en-1-one (Bi) was obtained.
The mechanism for the formation of $\Delta^{1}$-pyrrolines 4 invalves reduction of the nitro group to the corresponding amine intermediate II, which, after a cyclization and deydration sequence, affords the desired products. On the ther hand, formation of $\Delta^{1}$-pyrroline- $N$-oxides $\mathbf{5}$ as by-produts results from cyclization of the partially reduced bydroxylamine intermediate I (Scheme 4).

The synthesis of the novel $\Delta^{1}$-pyrroline derivatives $(R)$ $\mathbf{4 b}$-h occurred without racemization. All enantiomeric excosses were determined by HPLC analysis (see the Supporting Information). The absolute configuration of $\mathbf{4 d}$ and $\mathbf{4 e}$ were confirmed by X-ray diffraction studies (Figure 1). ${ }^{17}$

In conclusion, we have described a very efficient synthesis of $\Delta^{1}$-pyrroline derivatives through a one-pot nitroreduction, cyclization and dehydration sequence of $(R, E)$ -<smiles>[R7]c1ccc(/C=C/[C@H](CC(=O)c2ccc([R7])cc2)C[N+](=O)[O-])cc1</smiles>

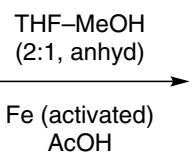

$(R)-3$<smiles>[R7]c1ccc(/C=C/[C@H]2CN=C(c3ccc([R7])cc3)C2)cc1</smiles>

$(R)-4$

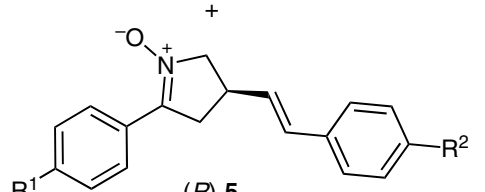

$(R)-5$

Scheme 3 Synthesis of highly enantioenriched $\Delta^{1}$-pyrroline derivatives<smiles>[R]c1ccc(/C=C/[C@H](CC(=O)c2ccc([R7])cc2)C[N+](=O)[O-])cc1</smiles>

$(R)-3$
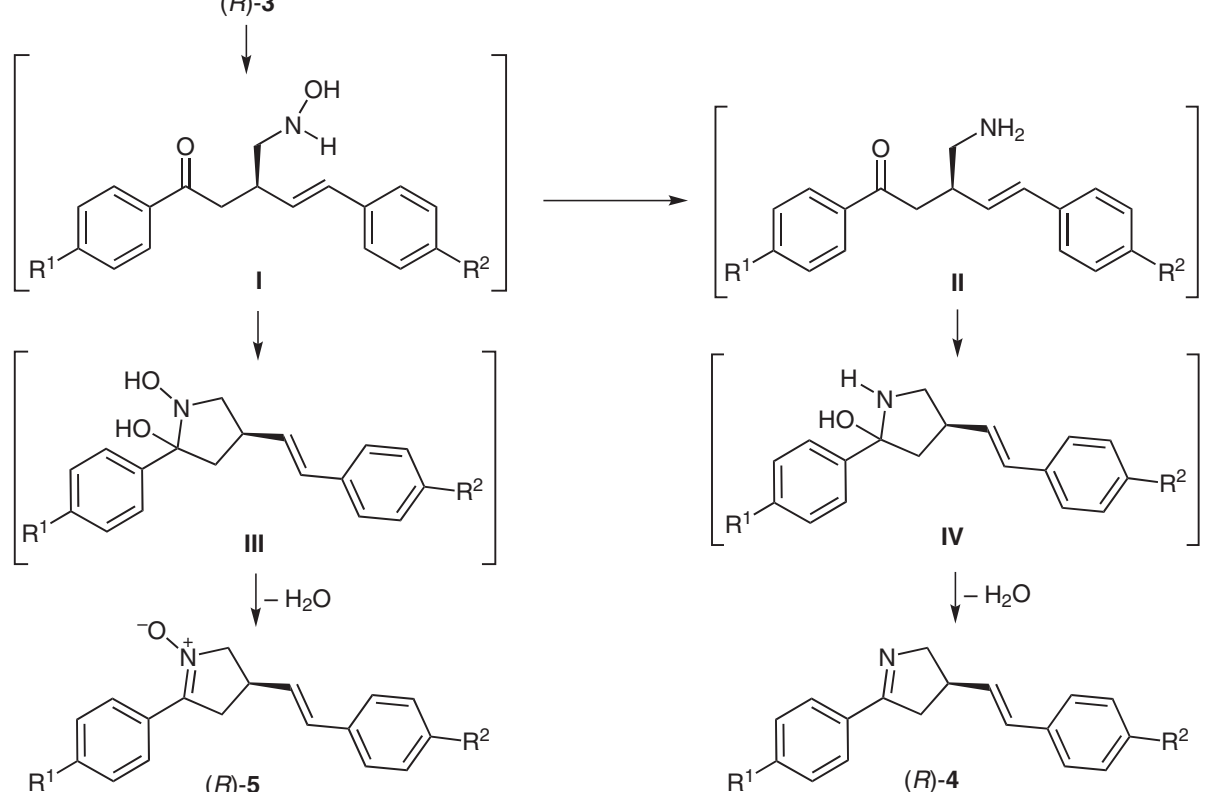

$(R)-5$

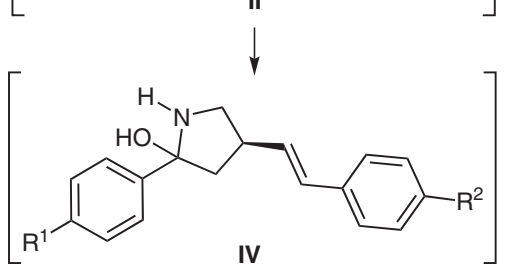

IV

$\downarrow-\mathrm{H}_{2} \mathrm{O}$<smiles>[R]c1ccc(/C=C/[C@H]2CN=C(c3ccc([Z17])cc3)C2)cc1</smiles>

$(R)-4$

Scheme 4 Proposed mechanism for the formation of the $\Delta^{1}$-pyrrolines $(R)-\mathbf{4}$ and $\Delta^{1}$-pyrroline- $N$-oxides 5

(c) Georg Theme Verlag Stuttgart New York - Synlett 2015, 26, 846-850 
a)

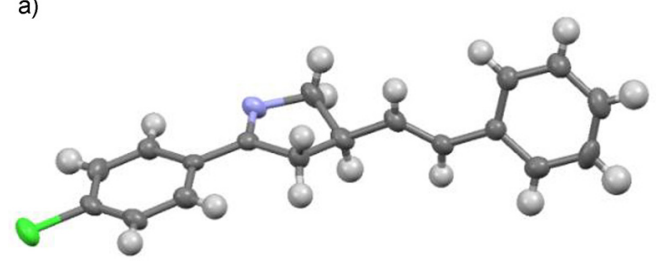

b)

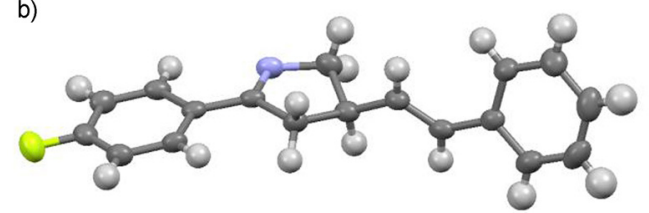

Figure 1 Molecular structure of $4 \mathbf{d}(\mathrm{a})$ and $\mathbf{4 e}(\mathrm{b})$. Thermal ellipsoids are shown at the $50 \%$ probability level, hydrogen atoms are shown with an arbitrary radius $(0.30 \AA)$. C, grey; $N$, blue; $\mathrm{Cl}$, green; F, yellow; $\mathrm{H}$, white

1,5-diaryl-3-(nitromethyl)-5-pent-4-en-1-ones 3. There was no racemization of the asymmetric carbon, and the trans-geometry of the double bond was retained. This methodology is being applied in our laboratory to the synthesis of $\Delta^{1}$-pyrroline boranyl complexes.

\section{Acknowledgment}

Thanks are due to the University of Aveiro and the Portuguese Fundação para a Ciência e a Tecnologia (FCT) for funding the Organic Chemistry Research Unit (project PEst- C/QUI/UI0062/2013), the CICECO Associate Laboratory (PEst-C/CTM/LA0011/2013) and the Portuguese National NMR Network (RNRMN). D.I.S.P.R. and S.G. also thank the FCT for a doctoral grant (SFRH/BD/62696/2009) and a postdoctoral grant (SFRH/BPD/70702/2010), respectively.

\section{Supporting Information}

Supporting information for this article is available online at http://dx.doi.org/10.1055/s-0034-1380144.

\section{References and Notes}

(1) Current address: Medicinal Chemistry Section, Experimental Therapeutics Programme, CNIO (Spanish National Cancer Research Centre), Madrid, Spain.

(2) Huang, P.-Q. Asymmetric Synthesis of Five Membered Ring Heterocycles, In Asymmetric Synthesis of Nitrogen Heterocycles; Royer, J., Ed.; Wiley-VCH: Weinheim, 2009.

(3) Pinder, A. R. Nat. Prod. Rep. 1992, 9, 491.

(4) Asghari, S.; Qandalee, M. Synth. Commun. 2010, 40, 2172.

(5) Cardona, F.; Rocha, J.; Silva, A. M. S.; Guieu, S. Dyes Pigm. 2014, $111,16$.

(6) Marrec, O.; Christophe, C.; Billard, T.; Langlois, B.; Vors, J.-P.; Pazenok, S. Adv. Synth. Catal. 2010, 352, 2825.

(7) Shvekhgeimer, M. G. A. Chem. Heterocycl. Compd. 2003, 39, 405.
(8) Black, D. S.; Edwards, G. L.; Evans, R. H.; Keller, P. A.; Laaman, S. M. Tetrahedron 2000, 56, 1889.

(9) Liang, Y.; Dong, D.; Lu, Y.; Wang, Y.; Pan, W.; Chai, Y.; Liu, Q. Synthesis 2006, 3301.

(10) Kawai, H.; Kitayama, T.; Tokunaga, E.; Matsumoto, T.; Sato, H.; Shiro, M.; Shibata, N. Chem. Commun. 2012, 48, 4067.

(11) Lee, M.; Lee, Y.-J.; Park, E.; Park, Y.; Ha, M. W.; Hong, S.; Lee, Y.J.; Kim, T.-S.; Kim, M.-h.; Park, H.-g. Org. Biomol. Chem. 2013, 11, 2039.

(12) Oliva, C. G.; Silva, A. M. S.; Paz, F. A. A.; Cavaleiro, J. A. S. Synlett 2010, 1123.

(13) Oliva, C. G.; Silva, A. M. S.; Resende, D. I. S. P.; Paz, F. A. A.; Cavaleiro, J. A. S. Eur. J. Org. Chem. 2010, 3449.

(14) Silva, E. M. P.; Silva, A. M. S.; Cavaleiro, J. A. S. Synlett 2011, 2740.

(15) A mixture of iron powder $(30 \mathrm{~g})$ and $10 \% \mathrm{HCl}(25 \mathrm{~mL})$ was stirred vigorously for $1 \mathrm{~min}$. The solution was then filtered off and the iron powder was washed successively with distilled water $(5 \times 25 \mathrm{~mL})$ and absolute $\mathrm{EtOH}(5 \times 25 \mathrm{~mL})$.

(16) Synthesis of 4a-h; General Procedure: To a solution of $(R, E)-$ 1,5-diaryl-3-(nitromethyl)-5-pent-4-en-1-ones $\quad \mathbf{3 a - h} \quad(0.31$ $\mathrm{mmol})$ in a mixture of THF-MeOH $(2: 1,6 \mathrm{~mL})$ was successively added at r.t., $\mathrm{AcOH}$ (4.98 mmol) and activated iron powder (14.0 mmol). The resulting mixture was heated at $65^{\circ} \mathrm{C}$ for $15 \mathrm{~h}$ under a nitrogen atmosphere. After cooling to r.t., the reaction mixture was filtered through Celite and rinsed with EtOAc. The resultant solution was washed with sat. aq $\mathrm{NaHCO}_{3}$, brine, dried over $\mathrm{Na}_{2} \mathrm{SO}_{4}$, filtered and concentrated under reduced pressure. The resulting residue was purified by column chromatography (hexane-EtOAc, 80:20). Finally the residues were crystallized from hexane-EtOAc to furnish the desired compounds $\mathbf{4 a - h}$.

Compound 4a: Yield: 72\%; brown oil. ${ }^{1} \mathrm{H}$ NMR (300 MHz, $\mathrm{CDCl}_{3}$ ): $\delta=7.85$ (dd, $\left.J=7.0,2.3 \mathrm{~Hz}, 2 \mathrm{H}, \mathrm{H}-2^{\prime}, 6^{\prime}\right), 7.45-7.19(\mathrm{~m}$, 8 H, H-3',5', H-4', H-2",6", H-3",5", H-4"), 6.47 (d, J = $15.8 \mathrm{~Hz}$, $1 \mathrm{H}, \mathrm{H}-\beta), 6.24$ (dd, $J=15.8,7.9 \mathrm{~Hz}, 1 \mathrm{H}, \mathrm{H}-\alpha), 4.33$ (dd, $J=15.6$, $7.2 \mathrm{~Hz}, 2 \mathrm{H}, \mathrm{H}-5$ ), 3.90 (dd, J = 15.6, 5.1 Hz, $1 \mathrm{H}, \mathrm{H}-5$ ), 3.36-3.19 (m, $2 \mathrm{H}, \mathrm{H}-3, \mathrm{H}-4), 2.97-2.81(\mathrm{~m}, 1 \mathrm{H}, \mathrm{H}-3) .{ }^{13} \mathrm{C}$ NMR $(75 \mathrm{MHz}$, $\left.\mathrm{CDCl}_{3}\right): \delta=172.7(\mathrm{C}-2), 137.1\left(\mathrm{C}-1^{\prime \prime}\right), 134.2\left(\mathrm{C}-1^{\prime}\right), 132.2(\mathrm{C}-\alpha)$,

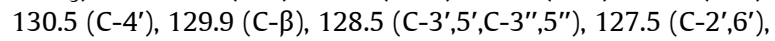
127.2 (C-4"), 126.0 (C-2",6"), 67.2 (C-5), 41.8 (C-3), 41.3 (C-4). HRMS (ESI $\left.{ }^{+}\right): m / z\left[\mathrm{C}_{18} \mathrm{H}_{17} \mathrm{~N}+\mathrm{H}\right]^{+}$calcd for $\mathrm{C}_{19} \mathrm{H}_{17} \mathrm{~N}: 248.1434$; found: 248.1433. HPLC ( $i$-PrOH-hexane, 10:90; flow rate 0.7 $\mathrm{mL} / \mathrm{min} ; \lambda=254 \mathrm{~nm}): t_{\mathrm{r}}=10.90[(R)-4 a] \min (e e=99 \%)$.

Compound 4e: Yield: $44 \%$; salmon solid; mp 110.6-111. ${ }^{\circ} \mathrm{C} .{ }^{1} \mathrm{H}$ $\operatorname{NMR}\left(300 \mathrm{MHz}, \mathrm{CDCl}_{3}\right): \delta=7.71\left(\mathrm{~d}, J=8.6 \mathrm{~Hz}, 2 \mathrm{H}, \mathrm{H}-2^{\prime}, 6^{\prime}\right), 7.55$ (d, $\left.J=8.6 \mathrm{~Hz}, 2 \mathrm{H}, \mathrm{H}-3^{\prime}, 5^{\prime}\right), 7.37-7.18$ (m, $5 \mathrm{H}, \mathrm{H}-2^{\prime \prime}, 6^{\prime \prime}, \mathrm{H}-3^{\prime \prime}, 5^{\prime \prime}$, H-4"), 6.46 (d, $J=15.8 \mathrm{~Hz}, 1 \mathrm{H}, \mathrm{H}-\beta), 6.23$ (dd, $J=15.8,8.2 \mathrm{~Hz}$, $1 \mathrm{H}, \mathrm{H}-\alpha), 4.38-4.24(\mathrm{~m}, 1 \mathrm{H}, \mathrm{H}-5), 3.94-3.82(\mathrm{~m}, 1 \mathrm{H}, \mathrm{H}-5)$, 3.38-3.16 (m, 2 H, H-3, H-4), 2.92-2.79 (m, $1 \mathrm{H}, \mathrm{H}-3) .{ }^{13} \mathrm{C}$ NMR $\left(75 \mathrm{MHz}, \mathrm{CDCl}_{3}\right): \delta=171.8(\mathrm{C}-2), 137.0\left(\mathrm{C}-1^{\prime \prime}\right), 133.2\left(\mathrm{C}-4^{\prime}\right)$, $132.0(C-\alpha), 131.7\left(C-3^{\prime}, 5^{\prime}\right), 130.2(C-\beta), 129.1\left(C-2^{\prime}, 6^{\prime}\right), 128.6$ (C3",5"), 127.4 (C-4"), 126.1 (C-2",6"), 125.1 (C-1'), 67.4 (C-5), $41.8(\mathrm{C}-3), 41.4(\mathrm{C}-4)$. HRMS $\left(\mathrm{ESI}^{+}\right): \mathrm{m} / z\left[\mathrm{C}_{18} \mathrm{H}_{16} \mathrm{BrN}+\mathrm{H}\right]^{+}$calcd for $\mathrm{C}_{18} \mathrm{H}_{17} \mathrm{BrN}$ : 326.0539; found: 326.0537. HPLC ( $i$-PrOHhexane, 10:90; flow rate $0.7 \mathrm{~mL} / \mathrm{min} ; \lambda=254 \mathrm{~nm}): t_{\mathrm{r}}=13.07$ $[(R)-4 \mathbf{e}] \min (e e=99 \%)$.

(17) Crystal data for 4d: $\mathrm{C}_{18} \mathrm{H}_{16} \mathrm{ClN}$; $M=281.77$; orthorhombic; space group P212121; $Z=4 ; a=5.6675(7) \AA, b=7.8846(12) \AA, c=$ 32.643(3) $\AA, \alpha=\beta=\gamma=90.00^{\circ} ; V=1458.7(3) \AA^{3}$; colorless crystal with crystal size of $0.10 \times 0.08 \times 0.04 \mathrm{~mm}$ was used. Of a total of 2942 reflections collected, 2022 were independent (Rint $=0.0968$ ). Final $R 1=0.0614[I>2 \sigma(I)]$ and $w R 2=0.1591$ (all data). Crystal data for 4e: $\mathrm{C}_{18} \mathrm{H}_{16} \mathrm{FN} ; M=265.32$; orthorhombic; space group P212121; $Z=4 ; a=5.6544(6) \AA$, $b=7.9709(8) \AA ̊, c=$ 
Synlett

D. I. S. P. Resende et al.

Letter

31.048(3) $\AA, \alpha=\beta=\gamma=90.00^{\circ} ; V=1399.4(2) \AA^{3}$; colourless flake with crystal size of $0.50 \times 0.20 \times 0.04 \mathrm{~mm}$. Of a total of 3068 reflections collected, 2834 were independent $($ Rint $=0.0380)$. Final $R 1=0.0336[I>2 \sigma(I)]$ and $w R 2=0.0796$ (all data). CCDC-
1033064 and 1033065 contain the supplementary crystallographic data for this paper. These data can be obtained free of charge from The Cambridge Crystallographic Data Centre via www.ccdc.cam.ac.uk/datarequest/cif. 